\title{
Understanding of closely spaced split injections of an outward- opening piezoelectric gasoline injector by large eddy simulations
}

\author{
Xinyan Wang*, Hua Zhao \\ Centre for Advanced Powertrain and Fuels, Brunel University London, Uxbridge UB8 3PH, \\ United Kingdom. \\ ${ }^{*}$ Corresponding author email: xinyan.wang@brunel.ac.uk
}

\begin{abstract}
The outward-opening piezoelectric injectors are capable to achieve precise and flexible controls of the fuel injection rate and duration with rapid opening and closing for split or multiple injections, which can minimise wall wetting and deposit formation in Gasoline Direct Injection (GDI) engines. However, experimental studies have shown that narrowly spaced split injections with short dwell time can increase cycle-to-cycle variation and emissions. In this study, large eddy simulations (LES) of an outward-opening piezoelectric gasoline injector were performed to understand the interactions between split injections and their impact on the flow fields, fuel/air mixing and transportation. The simulations were performed in a constant volume vessel and validated with experimental data. The results at both 1 bar and 10 bar backpressures showed that the droplets, fuel vapor and flow fields distributions were significantly affected by split injections when short dwells $(0.6 \mathrm{~ms}$ and $1 \mathrm{~ms})$ were applied. In particular, the fuel vapor distribution at recirculation zones of the spray where the spark plug is normally positioned was significantly changed after the second injection, compared to that of single injection, implying potential impact on the ignition stability.
\end{abstract}

\section{Keywords}

Large eddy simulation; split injections; atomisation; fuel distribution; gasoline direct injection.

\section{Introduction}

Fuel injection is one of the key in-cylinder processes directly affecting the combustion and emissions of internal combustion engines. The spray characteristics and injection strategies in both direct injection (DI) spark ignition engine and compression ignition (Cl) engine need to be well optimised to achieve better fuel/air mixing process and optimal combustion process. Compared to the port fuel injection (PFI) engines, the gasoline direct injection (GDI) engines enable more flexible control of the fuel/air mixture formation and more advanced combustion process, including lean combustion and highly diluted combustion with multiple injections. The outward-opening piezoelectric gasoline injector can produce stable hollow-cone spray pattern with a shorter penetration and a recirculation zone at the spray tip, while the spark plug is placed at the recirculation zone to enable faster and stable ignition. The piezoelectric actuator also enables precise and flexible controls of the fuel injection rate and duration with rapid opening and closing for split or multiple injections with short dwells, which can minimise wall wetting and deposit formation in GDI engines [1].

In order to achieve optimal combustion for the spark ignition operation, the fuel injection and local fuel/air equivalence ratio around the spark plug should be controlled to near stoichiometry for stable ignition and faster flame propagation [2-3]. Both the start of injection timing [4-6] and the split direct injection ratio [2, 7-8] of the split injections play important roles on controlling in-cylinder fuel stratification patterns and the subsequent combustion process. The engine performance, including thermal efficiency, exhaust emissions and cycle-to-cycle variation (CCV), can be worsened by simply implementing split injections without optimising split 
injection timings and dwell time between injection events [9-10]. In fact, the spray process influences the in-cylinder large scale flow structures and turbulence intensity, while the ambient gas flow motion also shows impact on the spray structures [11]. The study on the effect of split injections in a direct injection gasoline engine shows that the late injected fuel of the second pulse was affected more by the in-cylinder flow motion [12]. Parrish et al. [13] investigated closely spaced double injections of a multi-hole fuel injector and found that the fuel penetration of the second injection was affected by the residual flow field produced by the first injection. The measurements performed by Dhanji and Zhao [14] indicate stronger interactions between the injection events of the closely spaced split injections, which lead to larger Sauter mean diameters (SMDs). Optical measurements of the single nozzle injector performed by Wu et al. [15] found that the spray tip penetration rate of the second spray was slightly slower than that of the first spray at the beginning stage of injection, but it was significantly larger than the first one at the later stage. Skogsberg et al [16] investigated the spray characteristics of an outward-opening injector and found the droplets in the leading edge of the spray plume had lower velocity for split injections compared to a single injection event, providing an extended window of ignitable mixture at the spark plug.

In addition to the optical measurements, large eddy simulations have been extensively applied for the understanding of the spray dynamics [17-18]. Hadadpour et al. [19] performed an LES study of multiple-injection strategies of gaseous fuel and confirmed that the turbulence generated in the main injection was further enhanced when the post-injection flow into the main injection flow. They also applied LES to split injections of diesel fuel and found the penetration of the second injection was faster than that of the first injection [20]. The LES study of the multiple injections of $n$-dodecane by Zhao et al. [21] show that an increase in axial velocity can be seen for the second injection owing to the decrease in density and the effect of gas expansion.

The existing research indicated that there are strong interactions between split injections which dominate the development of spray characteristics. Although there are optical measurements of split injections of outward-opening injector, the interactions between closely spaced split injections are not fully understood. In this study, large eddy simulations (LES) were employed to understand the evolution of the closely spaced split injections of an outwardopening piezoelectric gasoline injector. The results were compared against the single injection strategy to clarify the difference of spray pattern, fuel distributions and flow fields. The mesh sensitivity and model validation were also discussed briefly in the paper.

\section{Methods}

Commercial CFD software STAR-CD [22] was used in this study. Large eddy simulations (LES) were performed by applying sub-grid k model [22-23], which has been widely used for the LES spray simulations. The standard wall treatment was implemented to model the nearwall turbulence. The heat transfer was implemented through the general form of the enthalpy conservation equation for the fluid mixture [24]. In order to depict the fuel spray process from the outward-opening piezo injector, the nozzle was defined explicitly by setting the effective nozzle hole diameter, inner and outer cone angles. The initial droplet size distribution was determined by Rosin-Rammler equations [25] and the model constants $X$ and q were fixed at $0.18 \mathrm{~mm}$ and 3.5, respectively. The O' Rourke model [22] and Bai model [26] were adopted to consider the inter-droplet collision and wall impingement, respectively. The Reitz Diwakar [27] model was applied to predict the droplet breakup process.

The Pressure-Implicit with Splitting of Operators (PISO) algorithm was used to solve the equations. The equations of momentum, turbulence kinetic energy and turbulence dissipation 
were discretized with the monotone advection and reconstruction scheme (MARS). The upwind differencing scheme (UD) and central differencing scheme (CD) were applied to discretize the temperature and density equations, respectively. The residual tolerance for the momentum, turbulence kinetic energy and turbulence dissipation was set at 0.01 while the residual tolerance for pressure and temperature was set at 0.001 to achieve good compromise between convergence and computational time.

Mesh sensitivity study was performed at first by using three meshes of the constant volume vessel with different grid sizes. Three grid sizes of the spray (central) zone, i.e. $0.5 \mathrm{~mm}$ (fine), $1 \mathrm{~mm}$ (medium) and $1.5 \mathrm{~mm}$ (coarse), were studied. The mesh size for the outer region was fixed at $4 \mathrm{~mm}$ for both fine and medium meshes to reduce the computational time, while it was $1.5 \mathrm{~mm}$ for coarse mesh. Figure 1 shows the section view of the fine mesh. The mesh sensitivity study of the LES with different meshes suggested that coarse and medium meshes produced shorter penetrations. Therefore, the fine mesh was adopted in this study. The timestep in the simulations was fixed at $0.0025 \mathrm{~ms}$ based on the sensitivity study of time-steps. The results of the mesh and time-step sensitivity study were not shown here for simplicity.

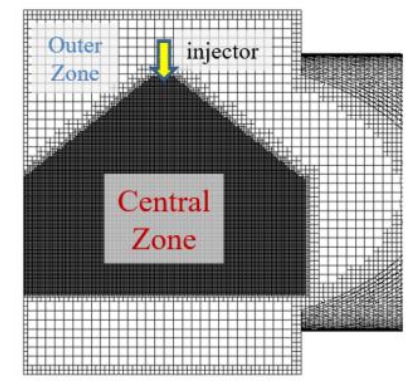

Figure 1. Simulation meshes with different mesh sizes.

The simulation models were validated against the corresponding spray measurements. The gasoline injection pressure and fuel temperature were 180 bar and $293 \mathrm{~K}$, respectively. The background temperature was fixed at $293 \mathrm{~K}$, and two background pressures (i.e. 1 bar and 10 bar) were measured. The background gas in the chamber was pure nitrogen $\mathrm{N}_{2}$. The gasoline fuel was adopted in the measurements and the set injection duration was fixed around $1.0 \mathrm{~ms}$. It should be noted that measured fuel flow rate indicated that the actual injection duration was around $1.2 \mathrm{~ms}$. In the simulations, all these initial and boundary conditions were kept the same as the measurements. As shown in Figure 2, the spray penetrations of LES results overall show good agreement with experimental measurements at both 1 bar and 10 bar backpressures. Therefore, the adopted simulation models were applied for the subsequent studies. In addition to the baseline single injection strategy, two split injection strategies were employed in the simulations. As shown in Table 1, Case Single is the single injection strategy with injection duration $\left(d_{1 s t}\right)$ of $1.2 \mathrm{~ms}$. The duration of the first $\left(d_{1 s t}\right)$ and second $\left(d_{2 n d}\right)$ injections was fixed at $0.6 \mathrm{~ms}$ for both split injection strategies. The dwell was $0.6 \mathrm{~ms}$ for Case Split-1 and $1 \mathrm{~ms}$ for Case Split-2. 
Table 1 - Injection strategies

\begin{tabular}{|l|l|l|l|}
\hline Case ID & $d_{1 \text { st }}(\mathrm{ms})$ & $d$ well $(\mathrm{ms})$ & $\mathrm{d}_{2 \mathrm{nd}}(\mathrm{ms})$ \\
\hline Single & 1.2 & - & - \\
\hline Split-1 & 0.6 & 0.6 & 0.6 \\
\hline Split-2 & 0.6 & 1 & 0.6 \\
\hline
\end{tabular}

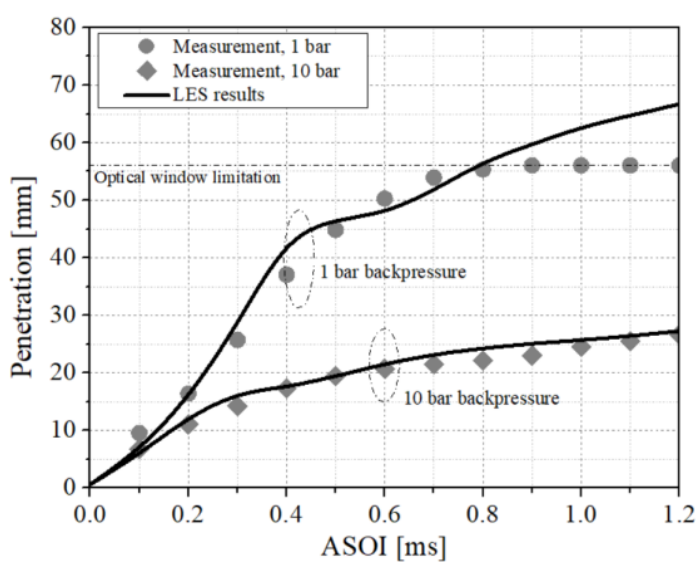

Figure 2. Validation of spray penetration against experimental measurements.

\section{Results and Discussion}

The results of distributions of spray droplets, fuel vapor concentration and flow fields at $0.8 \mathrm{~ms}$ at the end of injection (AEOI) at 1 bar backpressure are shown in Figure 3 for different injection strategies. The red dash lines indicate the injection direction of the spray jets from the nozzle. Overall, the spray droplets distribution show very similar pattern at the end of injections among different injection strategies. For the split injections, the second injection produced recirculation zone at the middle of the spray plume. It is even more obvious for the shorter dwell case (Case Split-1). Besides, the droplets penetration was longer for the split injections as droplets at the tip already touched the bottom of the spray chamber.

The distributions of fuel vapor concentration in Figure 3 show more differences among three injection strategies. For single injection strategy, it is clear that the air entrainment split the fuel vapor and produced two fuel vapor clouds at the middle of the spray plume and the leading edge of the plume. Two vortexes can be clearly observed at the downstream of the spray jets, and the fuel vapor was driven upwards accordingly. By using split injection strategies, the vortex structures formed by the first injection event was encountered by the second injection, therefore there was no distinct large vortex structure at the downstream of the spray jets as observed in single injection strategy for both split injection strategies. In Case Split-1 with shorter dwell, the fuel vapor cloud at the leading edge of the plume was not fully split before the second injection jet arrived. The induced flow motion from second injection dominated the air entrainment and split the fuel vapor from first and second injection into two clouds. However, it is noted that the fuel vapor mainly from the first injection at the leading edge developed further downstream compared to that of single injection strategy. In comparison, Case Split-2 with a longer dwell between two injections produced three recirculation zones of fuel rich vapor, as the first injection already produced two fuel rich clouds before second injection jet came. As the result, the fuel vapor cloud at the tip of second injection merged with the upstream fuel cloud formed during the first injection, while the fuel clouds at the upstream of second injection and downstream of first injection were also retained. 
Figure 4 shows the results at $0.8 \mathrm{~ms} \mathrm{AEOI} \mathrm{at} 10$ bar backpressure. The penetration was much shorter compared to the low backpressure cases due to much higher ambient gas density. Besides, only one recirculation zone was observed at the tip of the spray jet. The further development of the flow fields after the injection events also transported some fine droplets as well as fuel vapor into the central region (downstream of injector axis), which was also observed in optical studies [5, 16]. For the single injection strategy, a clear vortex structure was formed and sustained at the downstream of the spray jet and in turn transported fuel vapor upwards in the recirculation zone where the spark plug gap is normally positioned. In the meantime, the sustained vortexes at both sides also produced continuous downward flow motions along the injector axis and transported fine droplets and fuel vapor to the downstream. In the split injection strategies, the interactions between first and second injections clearly redistributed the recirculation zone and fuel rich mixture cloud. In Case Split-1 with relatively shorter dwell, the fuel rich vapor cloud was transported more to the downstream compared to the single injection case. However, in Case Split-2 with relatively longer dwell, the vortexes formed through second injection were rather weak, while the downward flow motion along the injector axis was enhanced due to the interactions between first and second injections. As the result, the rich fuel vapor clouds were transported to the central region closer to the injector axis and only limited fuel vapor from first injection was transported upwards above the red dash line towards spark plug.

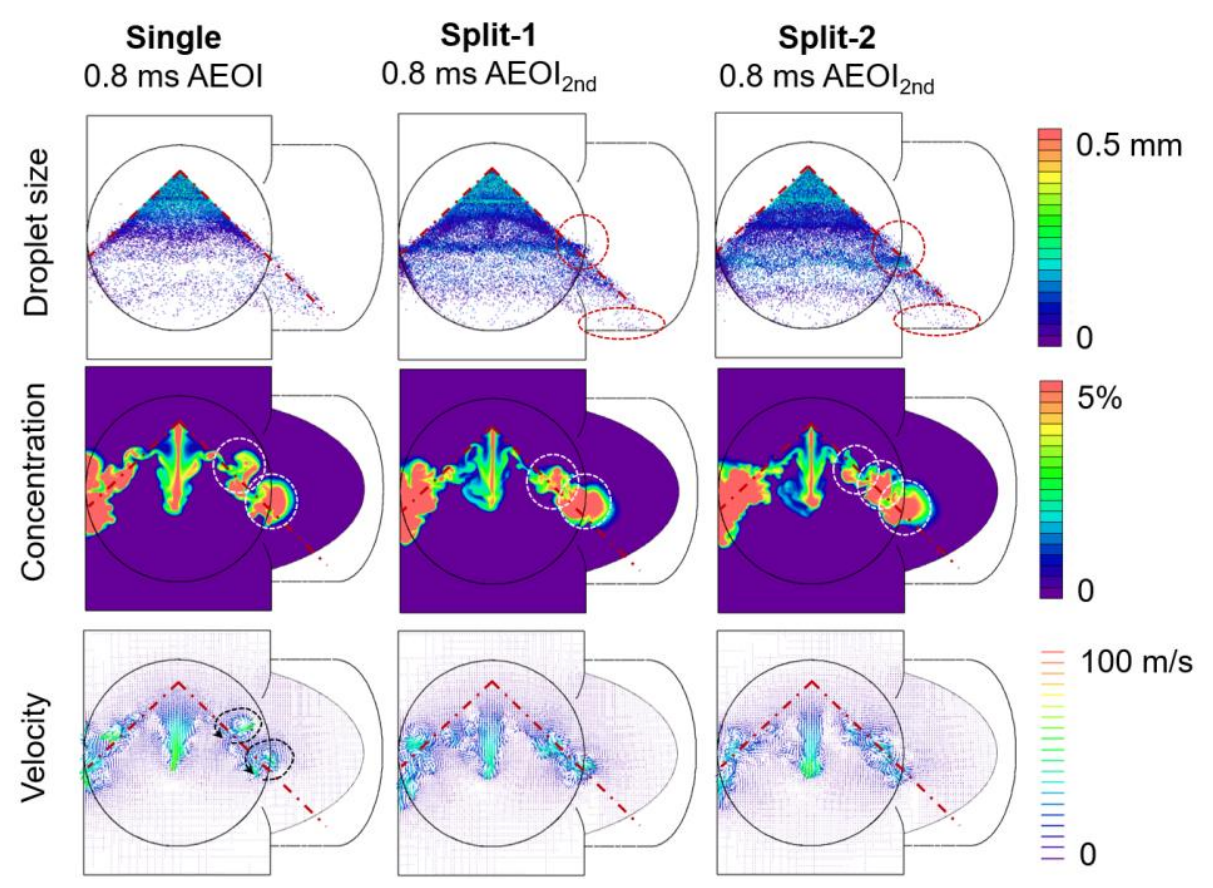

Figure 3. Spray droplets distribution (upper row) and distribution of fuel vapor concentration (middle row) and flow fields (lower row) for different injection strategies at 1 bar back pressure.

In order to further understand the interactions of split injections, Figure 5 shows the evolution of flow fields of $1^{\text {st }}$ injection of split injections, $2^{\text {nd }}$ injection of Split-1 and $2^{\text {nd }}$ injection of Split2. The flow fields at 1 bar backpressure are shown in the left three columns. At $0.4 \mathrm{~ms}$ after the start of injection (ASOI), the residual flow fields from $1^{\text {st }}$ injection in Case Split-2 travelled slightly more downstream compared to that in Case Split-1. However, it is noted that the spray induced flow fields in Case Split-2 travelled less downstream than that in $1^{\text {st }}$ injection and $2^{\text {nd }}$ injection of Case Split-1, as shown by the penetration of the high-speed vectors (in red). This indicates more disruption on the $2^{\text {nd }}$ injection by the residual flow fields in Case Split-2. At 0.8 
ms ASOI, the fast development of flow fields in Case Split-1 formed a large vortex in the middle of the spray jets and two vortexes in the downstream, while a serial of vortexes along the spray jets were formed in Case Split-2. Besides, the penetration of the high-speed vectors of $2^{\text {nd }}$ injection of Case Split-2 became larger compared to $1^{\text {st }}$ injection and $2^{\text {nd }}$ injection of Split-1. In addition to the downstream vortexes, a vortex at upstream formed at $0.8 \mathrm{~ms}$ ASOI was sustained at $1.2 \mathrm{~ms}$ ASOI in Case Split-2, which in turn produced three recirculation zones of the fuel rich mixture in Figure 3.

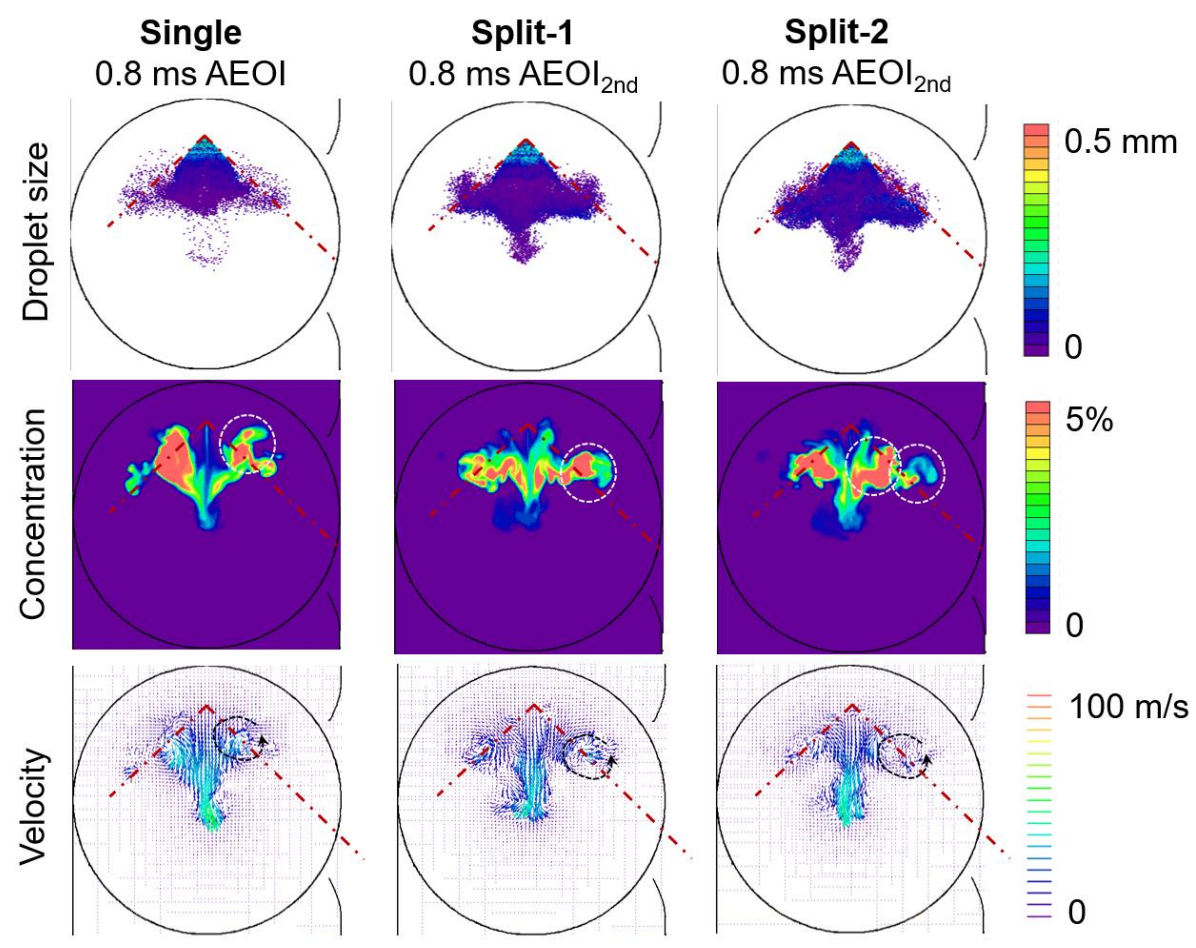

Figure 4. Spray droplets distribution (upper row) and distribution of fuel vapor concentration (middle row) and flow fields (lower row) for different injection strategies at 10 bar back pressure.

The right three columns in Figure 5 compare the flow fields at 10 bar backpressure. It is noted that the air entrainment occurred more downstream for the $2^{\text {nd }}$ injection at $0.4 \mathrm{~ms}$ ASOI. Besides, a vortex was already formed at the spray tip for the $2^{\text {nd }}$ injection with the help the residual flow fields by the first injection. More vortexes were then formed at $0.8 \mathrm{~ms}$ ASOI by the $2^{\text {nd }}$ injection and transported more to the downstream compared to the main vortex by the first injection. However, the vortexes show different characteristics for Split-1 and Split-2. Specifically, in Case Split-1, two anticlockwise vortexes and one clockwise vortex were formed tightly in a triangle zone at $0.8 \mathrm{~ms} \mathrm{ASOI}$, and a large vortex was sustained at the downstream of the spray jets at $1.2 \mathrm{~ms} \mathrm{ASOI}$. In comparison, Case Split-2 had faster propagation of the spray jets, which resulted in three anticlockwise vortexes lining up along the spray jets. As the result, the vortexes encountered each other and only a relatively weak vortex at upstream closer to the injector axis was sustained. Meanwhile, the flow fields at the spray tip towards downstream of the spray jets were also retained. These in turn explain the droplets and fuel vapor distributions in Figure 4.

The resulted spray penetration at the end of injection ( $0.8 \mathrm{~ms} \mathrm{AEOI)} \mathrm{is} \mathrm{shown} \mathrm{in} \mathrm{Figure} 6$. The results confirm that split injections produced longer spray penetration due to the enhancement from the residual flow fields by the $1^{\text {st }}$ injection. Specifically, a relatively longer dwell time could potentially produce a longer penetration with less direct interactions of flow fields at 
recirculation zones from $1^{\text {st }}$ and $2^{\text {nd }}$ injections.

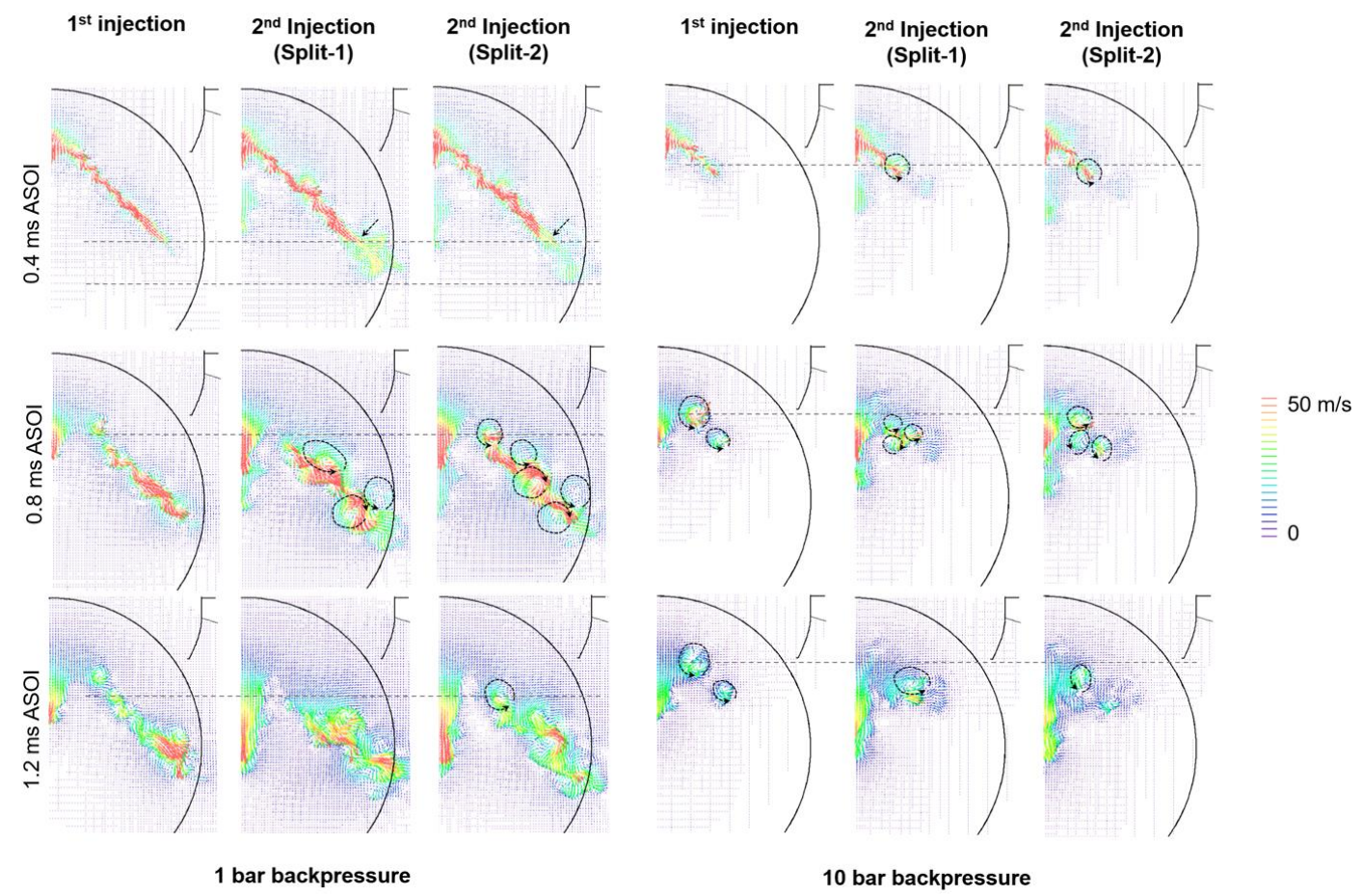

Figure 5. Evolution of flow fields of $1^{\text {st }}$ injection of split injections, $2^{\text {nd }}$ injection of Split-1 and $2^{\text {nd }}$ injection of Split-2 at 1 bar and 10 bar backpressures.

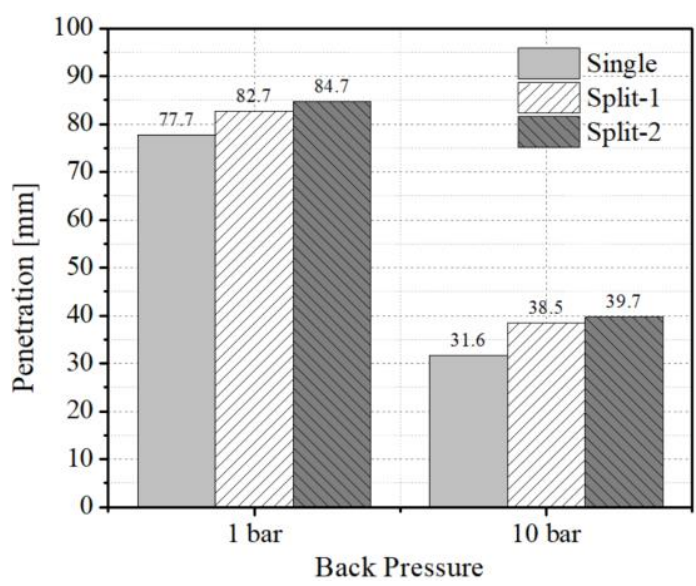

Figure 6. Spray penetration at $0.8 \mathrm{~ms}$ AEOI for different injection strategies.

\section{Conclusions}

Large eddy simulations were performed in this study to understand the spray development of an outward-opening injector with closely spaced split injections. The results indicated that the split injections with $0.6 \mathrm{~ms}$ and $1 \mathrm{~ms}$ dwells produced longer penetrations at the end of injection events $(0.8 \mathrm{~ms} A E O I)$ compared to the single injection strategies. The flow fields induced by second injection towards the downstream of spray jets were enhanced by the residual flow fields by the first injection compared to the single injection strategy. However, the capability to form large vortexes and recirculation zones was in turn weakened by split injections, implying potential impact on ignition stability.

At 1 bar backpressure, in Case Split-1 with $0.6 \mathrm{~ms}$ dwell, the second injection merged with the first injection and then dominated the formation of two recirculation zones/fuel rich clouds. When the dwell increased to $0.8 \mathrm{~ms}$ in Case Split-2, three fuel rich clouds were formed. Specifically, the formed fuel vapor cloud at the tip of second injection only merged with the 
upstream fuel cloud of the first injection, while the fuel clouds at the upstream of second injection and downstream of first injection were also retained.

At 10 bar backpressure, in Case Split-1, the fuel rich vapor cloud was transported more to the downstream compared to the single injection case. In Case Split-2 with relatively longer dwell, the vortexes formed through second injection were rather weak and closer to the injector axis, transporting fuel rich mixture towards the central region close to the injector axis.

The current work clarified strong interactions of closely spaced split injection events which fundamentally changed the spray penetration, flow fields and fuel rich cloud distributions. More quantitative analysis on spatial and temporal evolutions of recirculation zones (fuel concentration and Sauter mean diameter, SMD) will be needed to understand the potential impact on the combustion process in GDI engines. Besides, it is also interesting to understand the spray characteristics of split injections under much higher gasoline injection pressure (e.g. 350 bar) and background pressure and temperature which are more relevant to real engine operating conditions.

\section{Acknowledgments}

This work was supported by the UKRI Future Leaders Fellowship (MR/T042915/1). The data of this paper can be accessed from the Brunel University London data archive, figshare at https://doi.org/10.17633/rd.brunel.14797920.

\section{References}

[1] Drake M C and Haworth D C. 2007 P. Combust. Inst. 31 99-124.

[2] Persson H, Sjöholm J, Kristensson E, Johansson B, Richter M and Aldén M 2008 SAE Technical Paper 2008-01-2401.

[3] Benajes J, García A, Domenech V and Durrett R 2013 Appl. Therm. Eng. 52 468-77.

[4] Costa M, Sorge U and Allocca L 2012 Energ. Convers. Manage. 60 77-86.

[5] Oh H and Bae C 2013 Fuel 107 225-35.

[6] Dahlander P and Hemdal S 2015 SAE Technical Paper 2015-01-0745.

[7] Ikoma T, Abe S, Sonoda Y, Suzuki H, Suzuki Y and Basaki M 2006 SAE 2006-01-1259.

[8] Dahl D, Andersson M, Berntsson A, Denbratt I and Koopmans L 2009 SAE 2009-01-1785.

[9] Sun Z, Cui M, Wang H, Nour M, Li X, Xu M and Hung D 2020 Conf. on ASME 2020 Internal Combustion Engine Division Fall Technical Conference (American Society of Mechanical Engineers Digital Collection.

[10] Costa M, Sorge U, Merola S, Irimescu A, La Villetta M and Rocco V 2016 Energy 117 405-15.

[11] Han Z, Fan L and Reitz R D 1997 SAE Technical Paper 970884.

[12] Stiesch G, Merker G P, Tan Z and Reitz R D 2001 SAE Technical Paper 2001-01-0965.

[13] Parrish S E, Zhang G and Zink R J 2012 SAE International Journal of Engines 5 400-14.

[14] Dhanji M and Zhao H 2021 Int. J. Engine Res. 1830013335.

[15] Wu G, Zhou X and Li T 2019 Energies 124284.

[16] Skogsberg M, Dahlander P and Denbratt I 2007 SAE 2007-01-1409.

[17] Hu B, Musculus M P and Oefelein J C 2012 Phys. Fluids 2445106.

[18] Van Dam N and Rutland C 2016 Int. J. Engine Res. 3 291-315.

[19] Hadadpour A, Jangi M and Bai X S 2018 Fuel 234 286-95.

[20] Hadadpour A, Jangi M, Pang K M and Song Bai X 2019 P. Combust. Inst. 37 4709-16.

[21] Zhao W, Wei H, Zhou L and Lu Z 2021 Fuel 285119214.

[22] Cd-Adapco. 2014.

[23] Speziale C G 1991 Annu. Rev. Fluid Mech. 23 107-57.

[24] Jones W P 1980 Prediction methods for turbulent flames Prediction Methods for Turbulent

Flow ed W Kollmann (Washington, D.C.: Hemisphere) pp 1-45.

[25] Lefebvre A 1988 Atomization and sprays: CRC press.

[26] Bai C and Gosman A D 1995 SAE Technical Paper 950283.

[27] Reitz R D and Diwakar R 1986 SAE Technical Paper 860469. 